Document downloaded from:

http://hdl.handle.net/10251/158944

This paper must be cited as:

Conesa, C.; Laguarda-Miro, N.; Fito, P.; Seguí Gil, L. (2020). Evaluation of Persimmon (Diospyros kaki Thunb. cv. Rojo Brillante) Industrial Residue as a Source for Value Added Products. Waste and Biomass Valorization. 11(7):3749-3760.

https://doi.org/10.1007/s12649-019-00621-0

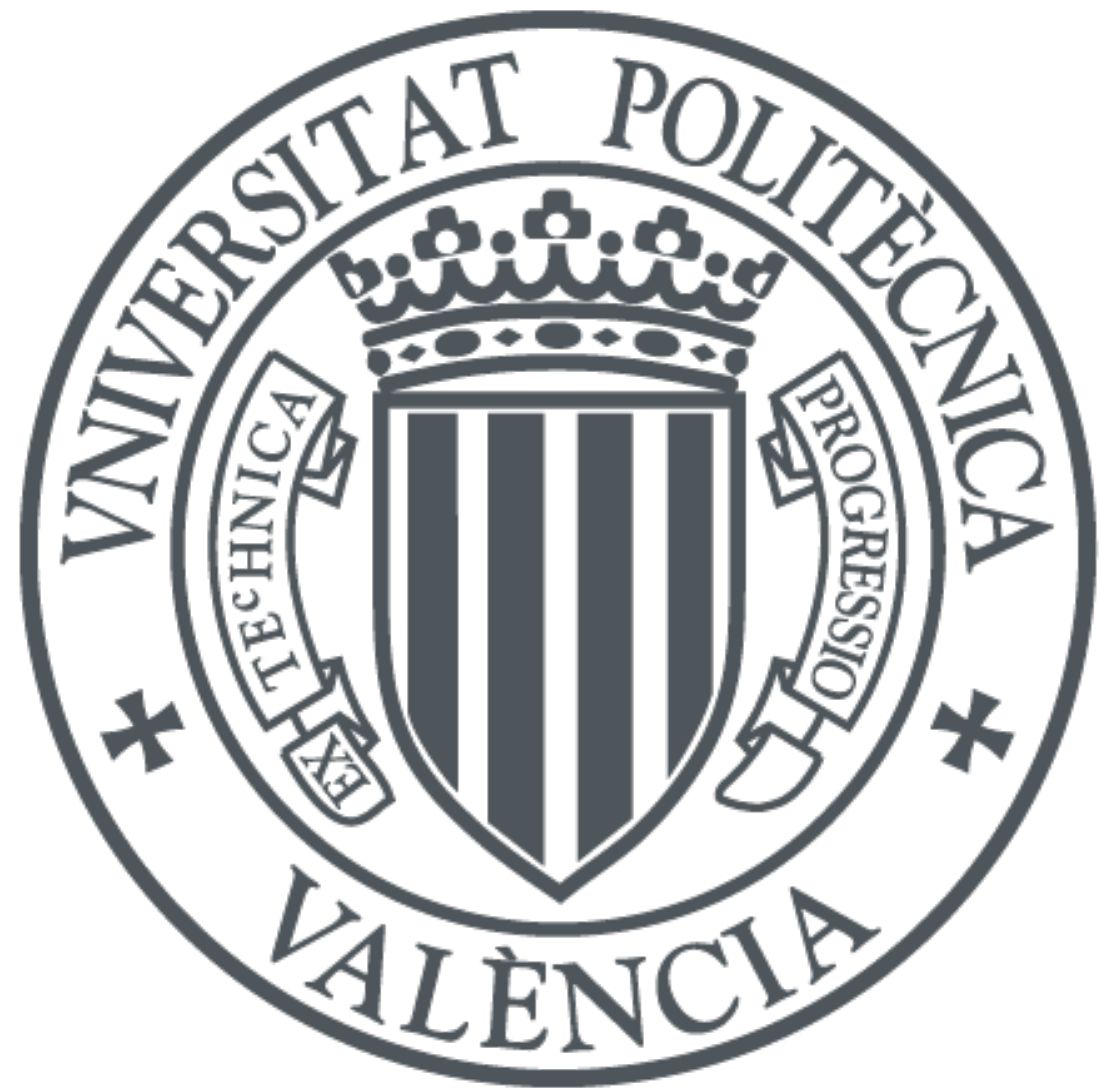

The final publication is available at

https://doi.org/10.1007/s12649-019-00621-0

Copyright Springer-Verlag

Additional Information 


\section{EVALUATION OF PERSIMMON (Diospyros kaki Thunb. cv. Rojo Brillante) INDUSTRIAL RESIDUE AS A SOURCE FOR VALUE ADDED PRODUCTS}

\section{Claudia Conesa ${ }^{1}$, Nicolás Laguarda-Miró ${ }^{2}$, Pedro Fito ${ }^{1}$, *Lucía $\underline{\text { Seguí }}^{1}$}

${ }^{1}$ Instituto de Ingeniería de Alimentos para el Desarrollo (IUIAD) - Universitat Politècnica de València, Camino de Vera s/n, 46022, Valencia, Spain.

${ }^{2}$ Centro de Reconocimiento Molecular y Desarrollo Tecnológico (IDM), Unidad Mixta Universitat Politècnica de València - Universitat de València, Camí de Vera s/n, 46022, Valencia, Spain.

*Corresponding author. Tel.: +34 963877000 Ext. 73676

E-mail address: lusegil@upvnet.upv.es

ORCID ID of corresponding author: 0000-0002-2711-9445

\section{Acknowledgements}

The authors would like to acknowledge the financial support of the Universitat Politècnica de València FPI grant programme and Anecoop S. Coop for facilitating the persimmon waste. 


\section{ABSTRACT}

\section{Purpose}

To evaluate the potential of the industrial waste of Rojo Brillante persimmon as a source for value-added products. The antioxidant compounds present in persimmon industrial waste (peel and calyx) and the suitability of this bagasse to be used as a substrate secondgeneration bioethanol production are studied and discussed. Both value-added products would contribute to the valorization of persimmon fruit residues, which are expected to increase to a higher extent in subsequent years, thus contributing to the food industry sustainability and circular economy.

\section{Methods}

Antioxidant properties were evaluated by analyzing total phenol content, soluble tannins, flavonoids and antioxidant capacity of the waste, consisting of the peel and calyx of the fresh-cut persimmon industry. In a different approach, several fermentation and saccharification processes were assayed in order to valorize the waste as a substrate for bioethanol production: direct fermentation (DF) of the waste (with water addition, sterilized or not) was carried out and compared with simultaneous saccharification and fermentation (SSF) of the waste (with and without water addition).

\section{Results}

The amount of phenols (59.2 $\pm 0.4 \mathrm{mg}$ AGE/100 g FW), flavonoids (7.5 $\pm 0.4 \mathrm{mg} \mathrm{QE} / 100$ $\mathrm{g} \mathrm{FW})$ and tannins $(11.43 \pm 0.08 \mathrm{~g} \mathrm{AGE} / 100 \mathrm{~g} \mathrm{FW})$, as well as the antioxidant capacity (16.67 mg TE/100 $\mathrm{g} \mathrm{FW)} \mathrm{of} \mathrm{persimmon} \mathrm{industrial} \mathrm{waste} \mathrm{were} \mathrm{in} \mathrm{the} \mathrm{range} \mathrm{of} \mathrm{the} \mathrm{pulp}$ values. Persimmon waste was especially rich in carotenoids: $\beta$-carotene $(400 \pm 7 \mu \mathrm{g} / 100$ $\mathrm{g}$ FW) and lycopene $(194.3 \pm 0.7 \mu \mathrm{g} / 100 \mathrm{~g} \mathrm{FW})$, these being values higher than in the whole fruit or pulp. Bioethanol production was more successful when a simultaneous saccharification and fermentation process was directly applied on the grinded waste (0.36 $\left.\pm 0.010 \mathrm{~g}_{\text {ethanol }} / \mathrm{g}_{\text {sugar }}\right)$, as compared to the other DF and SSF assayed.

\section{Conclusions}

Persimmon waste can be considered a good candidate for obtaining value-added products. Carotenoids could be extracted from this waste, but it is recommended to develop food ingredients in the form of flours of powders to be used as functional ingredients. Persimmon waste is also recommended as a substrate for second-generation bioethanol production, either alone or mixed with other food residual biomass. 
Keywords: Persimmon, antioxidants, carotenoids, food waste, waste valorization, second-generation bioethanol.

\section{Statement of novelty}

An increased production of persimmon fruit, especially of the Rojo Brillante variety, has led to surpluses and the search for new industrialized products which are yielding significant amounts of residues that need to be disposed. Valorization of this waste material is a must in order to contribute to the food industry sustainability and develop circular economy systems. This research presents persimmon waste as a good source for antioxidant compounds, especially carotenoids, but it also discusses persimmon waste as a substrate for the production of second generation bioethanol. This being of especial importance given recent European recommendations to reduce indirect land use change for biofuels and encourage the use of lignocellulosics and non-food cellulosic materials as a source for biofuels production.

\section{Introduction}

Persimmon (Diospyros kaki) is an important commercial fruit in Asia that has expanded rapidly in the Mediterranean basin [1]. In particular, the cultivation of the Rojo Brillante variety has increased considerably in Spain, having grown from 2,500 hectares in 2004 to almost 15,000 hectares in 2015, its production reaching 310,400 tons in 2016 [2]. Today, Asia continues to be the main producer worldwide (90.3\%), followed by Europe $(6.7 \%)$. The fast increase in the production and devoted cultivated surface is a result of the successful application of postharvest techniques in order to eliminate the astringency of the fruit, while fruit firmness and sweet flavour are preserved. Deastringency treatments consists of $48 \mathrm{~h}$ of exposure to a $\mathrm{CO}_{2}$ rich atmosphere, which converts soluble tannins into insoluble tannins and makes astringent varieties much appreciated and commercially viable $[3,4]$.

In spite of the improvement in post-harvesting techniques and storage methods, seasonality is still one of the drawbacks of persimmon fruit. Thus, one of the sector's priorities is to commercialize discarded produce and make use of market surpluses. Accordingly, a series of fruit derived products are being developed including dried persimmons [5], smoothies [6], sauces [7], juices and purées for the production of jams, cakes, pastries or bread [8], or either marketed as a fresh-cut commodity [9, 10]. The main 
consequence of the increasing cultivation and industrialization of this fruit is the generation of a significant amount of residue, which consists of the peel and calyx (Figure 1). In order to add value to these residues, some research has focused on the use of persimmon waste to produce vinegar [11], flours from persimmon peel to be used as food ingredients $[4,12]$, as well as peel fibers [13].

Persimmon has been claimed to have beneficial effects in fighting diabetes as well as a number of degenerative and cardiovascular diseases [14], due to the antioxidant compounds present in the fruit and, specifically, carotenoids. Takayuki [15] suggested that the fruit has chemo-preventative effects against several types of cancer cells. According to García-Alonso et al. [16] antioxidant activity in Rojo Brillante persimmon can be two fold higher than other excellent sources of antioxidant compounds such as blueberries or blackberries. Due to its antioxidant properties, persimmon has recently been processed to produce functional milkshakes [6] and juices [17]. Phenolic content in the persimmon fruits depends on the astringency of the fruit since deastringency practices result in a decreased antioxidant content [1]. As in most fruits, antioxidant capacity and total phenolic content is generally higher in the peel than in the pulp [18], for which persimmon industrial waste arises a potential source of bioactive compounds [19].

A different approach on the valorization of industrial persimmon waste consists of the evaluation of this residue as a substrate for microorganism growth and the production of interesting metabolites. In particular, there is great interest in the development of technologies for the use of agro-industrial biomass as a raw material for energy production. Bioethanol is the most important biofuel used worldwide, and can be used on its own (in modified engines), mixed with conventional gasoline, or either as an additive to replace methyl tert-butyl ether (MTBE), potentially toxic to humans [20]. It has the advantage or reducing $\mathrm{CO}_{2}$ and pollutants emissions into the atmosphere [21, 22]. Present trends in bioethanol production focus on developing processes for obtaining bioethanol from renewable resources at reasonable costs [21]. In fact, the directive EU/2015/1513 [23] to reduce indirect land use change for biofuels and bioliquids, specifically encourages the use of lignocellulosics and non-food cellulosic materials as a source for biofuels production.

Bioethanol production from lignocellulosic biomass usually involves two stages that can be carried out consecutively or simultaneously: the hydrolysis of cellulose and 
hemicellulose into mono and di-saccharides and the fermentation of the resulting sugars to obtain bioethanol. Hydrolytic enzymes used in the saccharification stage are usually obtained from fungi and consist of cellulases, which hydrolyze cellulose firstly into small oligosaccharides and then into glucose; and hemicellulases, which hydrolyse hemicellulose into monomeric sugars [24]. Simultaneous saccharification and fermentation (SSF) provides higher ethanol yield and lower energy consumption but usually requires higher concentration of enzymes, since control parameters are maintained closer to the optimum for fermentation than the optimum for enzymes performance $[25,26]$.

Current food transformation processes must not only focus on an adequate waste management, but mainly on the valorization of by-products in order to reintroduce them in the economic cycle. At present, there is great interest in developing processes for the valorization of food industrial residues in order to generate social and economic value, thus ensuring the continuity of the agricultural and rural activity [27, 28]. Integral valorization, process efficiency, circular economy, zero residue economy or biorefinery, all these terms serve to define this trend [29]. Hence, the main objective of this study was to evaluate the potential of the industrial waste of Rojo Brillante persimmon as a source for value-added products. In particular, the antioxidant compounds present in the industrial residue of this variety and the suitability of this bagasse to be used as a substrate for the production of second-generation bioethanol are studied and discussed. Both valueadded products would contribute to the valorization of persimmon fruit residues, which are expected to increase to a higher extent in subsequent years.

\section{Materials and Methods}

\subsection{Plant material and sample preparation}

Persimmon waste from cultivar Rojo Brillante (European Protected Designation of Origin (PDO) Kaki Ribera del Xúquer) was received from Anecoop S. Coop fresh-cut industry located in Valencia, Spain. Discarded waste material produced in the fresh packing lines which consisted mainly of the peel and calix of the fruit were used for the present work. In order to conduct the laboratory assays, persimmon waste was mashed in a blender (Avance Collection Blender HR2097/00 800 W, Philips, Amsterdam, the Netherlands) and stored at $-20^{\circ} \mathrm{C}$ until use.

\subsection{Physicochemical characteristics of persimmon waste}


Moisture content, water activity, total soluble solids (TSS), pH, fiber content and sugar profile were determined using the following methods. Water content was estimated by vacuum drying at $60^{\circ} \mathrm{C}$ until reaching constant weight (20.013 AOAC, 1980) [30]. Water activity was measured using a dewpoint hygrometer (DECAGÓN Aqualab CX-2). TSS were measured in Brix units with a table refractometer (ABBE ATAGO, NAR T3, Japan) at $20^{\circ} \mathrm{C}$, for which the liquid phase was extracted with a manual press. $\mathrm{pH}$ values were measured on the grinded waste using a calibrated potentiometer (Mettler Toledo Inlab). Fiber content was determined using the Van Soest official method [31] which allows for the estimation of cellulose, hemicellulose and lignin. Prior to the Van Soest analysis, persimmon grinded waste was freeze-dried in a lyophilizer (Lioalfa-6, Telstar®).

Identification and quantification of sugars were performed by High-Performance AnionExchange Chromatography with a Pulsed Amperometric Detector (HPAEC-PAD), using a Metrohm IC chromatograph system (Herisau, Switzerland) equipped with a 716 Compact module and an ICnet 2.0 software program for data analysis. Sugar extraction was conducted as suggested by Veberic et al. [32]. Thus, $10 \mathrm{~g}$ of the grinded fruit waste were blended with $50 \mathrm{ml}$ of bidistilled water and shaken for $30 \mathrm{~min}$ at room temperature with a magnetic stirrer (BASIC ACS-160 model, SBS® Instruments S.A., Barcelona, Spain). Then, the sample was centrifuged at $10,000 \mathrm{rpm}$ for $7 \mathrm{~min}$ at $10^{\circ} \mathrm{C}$. Finally, the supernatant was filtered through a $0.45 \mu \mathrm{m}$ nylon filter and diluted $(1: 2000 \mathrm{v} / \mathrm{v}$ with bidistilled water) to proceed with the chromatographic method. A three-step PAD setting was used with the following time periods (ms) and potentials (V): $\mathrm{t}_{1}, 400 \mathrm{~ms} / \mathrm{E}_{1}=+0.05$ $\mathrm{V}$ (detection); $\mathrm{t}_{2}, 200 \mathrm{~ms} / \mathrm{E}_{2}=+0.75 \mathrm{~V}$ (cleaning); $\mathrm{t}_{3}, 400 \mathrm{~ms} / \mathrm{E}_{3}=-0.15 \mathrm{~V}$ (regeneration). For separation, a Metrosep Carb 1 250/4.6 column (250 mm x 4.6 mm I.D.) was coupled to a guard column at $32{ }^{\circ} \mathrm{C}, 8.8 \mathrm{MPa}$, injection volume of $20 \mu \mathrm{L}$ and using sodium hydroxide $0.1 \mathrm{M}$ as the mobile phase $(1 \mathrm{ml} / \mathrm{min})$. Standards of glucose, fructose and sucrose (purity $\geq 99 \%$, Sigma-Aldrich, Spain). were used to prepare standard calibration curves (2.5 ppm, $5 \mathrm{ppm}, 10 \mathrm{ppm}, 15 \mathrm{ppm}, 25 \mathrm{ppm}$ and $50 \mathrm{ppm})$. All analytical determinations were performed in triplicates, so that given values correspond to the average and standard deviation.

\subsection{Evaluation of antioxidant properties of persimmon waste}

Antioxidant properties of persimmon waste were evaluated in terms of total phenolic content, soluble tannins, total flavonoid content, carotenoids content and DPPH-radical 
scavenging capacity. Determinations were performed in triplicate, results given as the average \pm standard deviation.

\subsubsection{Total phenolic content.}

The extraction of total phenolics was carried out according to the protocol described by Veberic et al. [32]. Thus, $20 \mathrm{ml}$ of methanol (PanReac® AppliChem, Barcelona, Spain purity $=100 \%$ ) and $5 \mathrm{~g}$ of waste were blended and kept in an ultrasonic bath for $30 \mathrm{~min}$ at room temperature (USC300T model, VWR® Ultrasonic cleaner, Radnor, PA, USA). After extraction, samples were centrifuged (Medifriger BL-S, J.P. Selecta®, Barcelona, Spain) for $7 \mathrm{~min}$ at $1,000 \mathrm{rpm}$ and $10^{\circ} \mathrm{C}$ and the supernatant was filtered through a 0.45 $\mu \mathrm{m}$ nylon filter (Filtros Anoia S.A., Barcelona, Spain). Then, total phenolic content was analyzed spectrophotometrically with the Folin-Ciocalteau reagent method [33]. $6 \mathrm{ml}$ of distilled water, $100 \mu \mathrm{l}$ of the sample extract and $500 \mu \mathrm{l}$ of Folin-Ciocalteu reagent were mixed and kept for $6 \mathrm{~min}$ at room temperature. Then, $1.5 \mathrm{ml}$ of a $20 \%$ of sodium carbonate solution was added. After $90 \mathrm{~min}$, the absorbance was measured at $760 \mathrm{~nm}$ using a spectrophotometer (632OD, Jenway, Stone, UK). The measurement was compared to a standard curve of gallic acid (99.7\% purity, Sigma-Aldrich, Spain) solutions in the range of 0.1 to $3 \mathrm{mg} / \mathrm{ml}$ and expressed as gallic acid equivalents (GAE) in $\mathrm{mg}$ per $100 \mathrm{~g}$ of fresh weight $(\mathrm{FW})$. A mixture of water and reagents was prepared as a blank. Folin-Ciocalteu reagent and sodium carbonate (purity $=99.8 \%$ ) were purchased from Sigma-Aldrich, Co.

\subsubsection{Soluble tannins.}

Soluble tannins content was analyzed using the Folin-Denis method as in Del Bubba et al [1]. Thus, $5 \mathrm{~g}$ of the crushed persimmon waste were added to a $25 \mathrm{ml}$ of methanol $80 \%$ solution and kept in an ultrasonic bath for $30 \mathrm{~min}$ at room temperature. Samples were centrifuged at $10,000 \mathrm{rpm}$ for $20 \mathrm{~min}$ at $4{ }^{\circ} \mathrm{C}$ and vacuum filtered and the supernatant was stored at $4{ }^{\circ} \mathrm{C}$. More supernatant was extracted from the precipitate by repeating homogenization, centrifugation and filtration operations. The total supernatant was brought to $100 \mathrm{ml}$ with distilled water. Next, $1 \mathrm{ml}$ of this sample solution, $6 \mathrm{ml}$ of distilled water and $0.5 \mathrm{ml}$ of Folin-Denis reagent were added and stirred. After $3 \mathrm{~min}, 1 \mathrm{ml}$ of 20\% $\mathrm{Na}_{2} \mathrm{CO}_{3}$ and $1.5 \mathrm{ml}$ of distilled added water were added and stirred. The absorbance was measured after 90 min with a spectrophotometer at $725 \mathrm{~nm}$. The measurement was 
compared to a standard curve of gallic acid solutions and expressed as GAE in g per 100 $\mathrm{g}$ of FW. Blank was prepared in the same way without adding sample.

\subsubsection{Total flavonoid content.}

Total flavonoids were determined according to Luximon-Ramma et al. [34] using the aluminum chloride colorimetric method. Sample extraction was conducted as described in 2.2.1. section. $1.5 \mathrm{ml}$ of a solution of $2 \%(\mathrm{~m} / \mathrm{v}) \mathrm{AlCl}_{3}$ in methanol was added to $1.5 \mathrm{ml}$ of the extract sample. The mixture was vigorously shaken and the absorbance was read at $337 \mathrm{~nm}$ after 10-15 min of incubation. The measurement was compared to a standard curve of quercetin solutions and expressed as quercetin equivalents (QE) (95\% purity, Sigma-Aldrich, Spain) in mg per $100 \mathrm{~g}$ of FW. A mixture of water and reagents was used as a blank. Aluminum chloride $\left(\mathrm{AlCl}_{3}\right)$ (purity $\geq 98 \%$ ) was also purchased from SigmaAldrich, Spain.

\subsubsection{Carotenoid content.}

Lycopene and $\beta$-carotene contents were determined by UV-vis spectrophotometry. Spectrophotometric measurements for carotenoids determinations are still widely used [35] and they have the advantage of rapidly assessing the lycopene and $\beta$-carotene content of different vegetables products, as compared to HPLC methods [36]. Hexane (purity = 95\%, Sigma-Aldrich) was used for carotenoids extraction. Accordingly, $20 \mathrm{ml}$ of ethanol and $15 \mathrm{ml}$ of hexane were added to $5 \mathrm{~g}$ of sample. The mixture was horizontally shaken (UNITRONIC-OR, J.P. Selecta ${ }^{\circledR}$ ) for 1 hour in order to enhance carotenoids extraction. Next, $1 \mathrm{ml}$ of distilled water was added to separate the soluble and liposoluble phases. Finally, the spectrophotometric measurement was performed by collecting $0.5 \mathrm{ml}$ of the apolar phase at $503 \mathrm{~nm}$ and $478 \mathrm{~nm}$, for lycopene and $\beta$-carotene measurements respectively. Blank was prepared with hexane. Lycopene and $\beta$-carotene contents were calculated using equation 1 and 2 :

$$
\begin{array}{ll}
\text { Lycopene }(\mathrm{mg} / 100 \mathrm{~g}) & =\frac{\mathrm{A}_{503} \cdot \mathrm{Mw} \cdot \mathrm{V}}{\mathrm{m} \cdot \mathrm{E}} * 100 \quad \text { Equation } 1
\end{array}
$$

Where $\mathrm{A}_{503}=$ Absorbance at $503 \mathrm{~nm} ; \mathrm{Mw}=$ molecular weight of lycopene $(537 \mathrm{~g} / \mathrm{mol})$; $\mathrm{V}=$ hexane phase volume $(\mathrm{ml}) ; \mathrm{m}=$ sample weight $(\mathrm{g}) ; \mathrm{E}=$ lycopene Extinction Coefficient in hexane $(172,000 \mathrm{~m} / \mathrm{m})[37]$. 


$$
\beta \text {-carotene }(\mathrm{mg} / 100 \mathrm{~g})=\frac{\left[\mathrm{A}_{478}-\left(\mathrm{A}_{503} \cdot 0,9285\right)\right] \cdot \mathrm{Mw} \cdot \mathrm{V}}{\mathrm{m} \cdot \mathrm{E}} \quad \text { Equation } 2
$$

Where $\mathrm{A}_{503}=$ Absorbance at $503 \mathrm{~nm} ; \mathrm{A}_{478}=$ Absorbance at $478 \mathrm{~nm} ; \mathrm{Mw}=$ molecular weight of $\beta$-carotene $(533.85 \mathrm{~g} / \mathrm{mol}) ; \mathrm{V}=$ hexane phase volume $(\mathrm{ml}) ; \mathrm{m}=$ sample weight $(\mathrm{g}) ; \mathrm{E}=\beta$-carotene Extinction Coefficient in hexane $(139,000 \mathrm{~m} / \mathrm{m})$ [37].

\subsubsection{Antioxidant capacity by the DPPH Free Radical Scavenging Assay}

The antioxidant activity of persimmon waste was assessed by determining the radical scavenging activity through the DPPH method as described by [38] with some modifications. Extraction of antioxidant compounds was conducted by adding $10 \mathrm{~mL}$ of $80 \%(\mathrm{v} / \mathrm{v})$ methanol-water dissolution to $5 \mathrm{~g}$ of crushed persimmon waste and stirring for $2 \mathrm{~min}$. Then the sample was centrifuged at $4000 \mathrm{rpm}$ and $10^{\circ} \mathrm{C}$ for $5 \mathrm{~min}$. Then the supernatant was stored at $0-4{ }^{\circ} \mathrm{C}$ before analysis. $3.9 \mathrm{ml}$ of a DPPH solution (80:20; methanol:water) was added to $0.1 \mathrm{ml}$ of the obtained supernatant. The mixture was kept in a dark place at room temperature for $30 \mathrm{~min}$ and the absorbance of the sample was measured at $515 \mathrm{~nm}$. Methanol was used as a blank. The percentage of DPPH inhibition was determined using the equation 3:

$$
\% \text { DPPH inhibited }=\frac{A_{\text {blank }}-A_{\text {sample }}}{A_{\text {blank }}} \times 100 \quad \text { Equation } 3
$$

where $A_{\text {blank }}=$ Absorbance of the blank; $A_{\text {sample }}=$ Absorbance of the sample.

Results were compared with a standard Trolox curve and expressed as mg of Trolox equivalents (TE) in $100 \mathrm{~g}$ of FW. DPPH and 6-hydroxy-2,5,7,8-tetramethylchroman-2carboxylic acid (trolox) (purity $\geq 97 \%$ ) were purchased from Sigma-Aldrich.

\subsection{Saccharification and fermentation for bioethanol production.}

\subsubsection{Preparation of inoculum.}

Ethanol-producing yeast strain Saccharomyces cerevisiae Meyen ex E.C. Hansen 1883 provided by the Colección Española de Cultivos Tipo (CECT) of the Universitat de València was used (CECT 1319). The lyophilized yeast was reconstituted and kept on yeast malt Agar (YM Agar, Scharlab. S.L., Barcelona, Spain) at $4{ }^{\circ} \mathrm{C}$. The inoculum was 
prepared by growing the microorganisms in tubes containing $3 \mathrm{~mL}$ of sterile Yeast Extract Peptone Dextrose broth (YEPD broth, Scharlab. S.L., Barcelona, Spain) in a laboratory incubator (Incudigit, J.P. Selecta ${ }^{\circledR}$ ) during $48 \mathrm{~h}$ at $28^{\circ} \mathrm{C}$, in order to obtain an inoculum medium containing 6.3 Log Colony Forming Units per mL ( $\left.\log \mathrm{CFU} \mathrm{mL} \mathrm{m}^{-1}\right)$.

\subsubsection{Saccharification and fermentation experiments.}

Fermentations were performed either directly in the solid waste (DF: Direct Fermentation), or by simultaneously hydrolyzing polymeric sugars in a Simultaneous Saccharification and Fermentation (SSF) process (figure 2). In order to perform the experiments, persimmon waste was first grinded in a blender (Solac Inox Professional 1000 W Mixer).

Persimmon waste was diluted before the DF process since, according to Sassner et al. [39], since high solid loadings of biomass increase viscosity preventing homogeneity and effective distribution of microorganisms. Therefore, persimmon waste was diluted by adding distilled water $(25 \% \mathrm{v} / \mathrm{v})$ before undergoing fermentation. Next, $1 \mathrm{~mL}$ of the prepared inoculum $\left(2 \cdot 10^{6} \mathrm{CFU}\right.$ S. cerevisiae $)$ were inoculated to $50 \mathrm{~g}$ of the diluted waste, in $100 \mathrm{~mL}$ Erlenmeyer flasks. The need for a previous thermal treatment in order to prevent microbial spoilage was evaluated by introducing the diluted waste in an autoclave (Systec GmbH, VB-40 model, Linden, Germany) at $121^{\circ} \mathrm{C}$ for $5 \mathrm{~min}$. Fermentations were underwent at pH 5 (adjusted with $\mathrm{HCl} 37 \%$ v/v, PanReac® AppliChem) and $28^{\circ} \mathrm{C}$ during 72 hours in a laboratory incubator. Experiments were conducted in triplicate.

Saccharification of the waste material was also assayed in order to maximize the amount of sugars available for fermentation. A simultaneous saccharification and fermentation process was chosen since, according to the cited literature, SSF may imply an increase in the ethanol yield as compared to a consecutive saccharification and fermentation process [26]. $1 \%(\mathrm{w} / \mathrm{w})$ cellulase $(1.13 \mathrm{U} / \mathrm{mg})$ and hemicellulase $(1.5 \mathrm{U} / \mathrm{mg}$ solid) enzymes from Aspergillus niger (1. Sigma-Aldrich., Spain) were added to the grinded diluted waste (medium) together with the S. cerevisiae inoculum. SSF was also assayed in non-diluted waste, since the action of the enzymes is expected to reduce the medium viscosity and facilitate enzyme and microorganism distribution. In addition, higher solid loads reduce substrate inhibition allowing for higher final concentration of products and has several environmental advantages since the agro-industrial wastes can be used in their natural 
form and wastewater production is reduced [40]. Besides reducing water consumption and effluents generation, high gravity media help in cutting down further steam consumption resulting in lower distillation costs [41]. Settled conditions for SSF were similar to the DF process.

\subsubsection{Analytical determinations.}

Colony Forming Units (CFU), sugar profile (glucose, fructose, sucrose), $\mathrm{pH}$ and ethanol content were determined at different time intervals ( $0 \mathrm{~h}, 24 \mathrm{~h}, 48 \mathrm{~h}$ and $78 \mathrm{~h})$ during the fermentation experiments.

Sugar extraction and $\mathrm{pH}$ measurements were performed as described previously. CFU were determined by the serial dilution method, by serially diluting in 5 tubes containing $9 \mathrm{~mL}$ of a $0.9 \% \mathrm{NaCl}$ solution. $0.1 \mathrm{~mL}$ of the less concentrated tubes were plated in YPDagar medium in order to obtain the 10-4, 10-5 and 10-6 dilutions. Counting was performed on plates containing 30 to $300 \mathrm{CFU}$ after $48 \mathrm{~h}$ of incubation at $28{ }^{\circ} \mathrm{C}$. Ethanol concentration (\% ethanol) was determined with an ethanol assay kit (ethanol-UV method) from Roche Diagnostics S.L. (Barcelona, Spain), based in various spectrophotometric measurements performed on a dilution of the sample $(1: 1000 \mathrm{v} / \mathrm{v}$ in bidistilled water), after reacting with the enzymes provided. Measurements were performed at $340 \mathrm{~nm}$ and the ethanol percentage calculated by the relationship given in the kit specifications. Results are shown as the average and standard deviations from triplicates.

\subsection{Statistical analysis}

Statgraphics Centurion XVI® (Manugistics Inc.; Rockville, MD, USA) was used for statistical analyses. Statistically significant differences were determined by using oneway analyses of variance (ANOVA) at $95 \%$ confidence level (p-value < 0.05 ).

\section{Results and discussion}

\subsection{Physicochemical characteristics of persimmon waste (peel and calyx)}

Physicochemical characteristics of persimmon waste are summarized in table 1. Results indicate that $\mathrm{pH}$, moisture content and water activity of the waste material are appropriate for microbial growth. Regarding initial sugar content in the liquid phase of persimmon waste, glucose and fructose were found in similar amounts, being fructose slightly higher. Although literature suggests that sucrose is also present in the flesh of mature fruits [1, 
32], it was not detected in the present study. One of the reasons for that absence could be the high invertase activity of persimmon fruit (two fold higher than apples according to Hirai and Kondo [42]. Similar results were obtained by Lucas-González et al. [4] who, apart from invertase activity, attributed the absence of sucrose to several factors such as extraction methods, deastringency treatment or, as it is the case of our study, the type of sample (residue vs. whole fruit). Total soluble solids obtained by refractometry could be considered an indirect measure of sugar content; nevertheless, this measurement can also reflect the presence of other components such as organic sugars or tannins [43]. Fiber content in persimmon waste suggests that there are some polymeric chains susceptible to be converted to simple sugars by the action of cellulase and hemicellulase enzymes.

\subsection{Antioxidant properties of persimmon waste}

Antioxidant properties of persimmon waste are summarized in Table 2. Total phenolic content, soluble tannins, total flavonoids, carotenoids ( $\beta$-carotene and lycopene) and antioxidant capacity values are given.

It is known that simple polyphenols together with highly polymerized flavanols are present in the fruit and, among the phenolic compounds in fully ripe persimmon fruit, catechin and gallic acid are the predominant [44]. Phenolic content of the fruit can vary significantly depending on the ripening stage or the astringency of the cultivar studied $[43,44]$. In astringent cultivars, reported polyphenol content is between $1.3 \mathrm{mg} \mathrm{GAE} / 100$ $\mathrm{g}[45,46]$ and $1480 \mathrm{mg} \mathrm{GAE} / 100 \mathrm{~g}$ of product [47]. In addition, the wide variability reported in the literature may not only be due to the type of astringent cultivar analyzed, but also to the environment and the extraction method used in the analysis [43]. Treatment with $\mathrm{CO}_{2}$ used to eliminate astringency decreases the total phenol content in the fruit [1, 43]. In particular, Del Bubba et al. [1] reported a total phenolic content of $220 \mathrm{mg}$ GAE/100 g in persimmons treated with ethanol vs. $31 \mathrm{mg}$ GAE/100 $\mathrm{g}$ for those treated with $\mathrm{CO}_{2}$, after a methanol-water extraction on the Rojo Brillante variety. Results of the present study reveal that the phenolic content in deastringent Rojo Brillante persimmon waste is above the values reported in the literature for the whole fruit. This is consistent with other authors' work who state that bioactive compounds present in the peel and other residues may be higher to that contained in the pulp or the whole fruit [18]. As compared to other residues [19] total phenols in persimmon peel are in the range of the the values reported for peels from pear or red ( 60 mg GAE/100 g), higher than peach or water 
melon peels (20-40 mg GAE/100 g), and lower than apple or orange peels (100-160 mg GAE/100 g).

As for total flavonoids, although they have been said to represent a very small part of the phenols present in the fruit (between 0.8-2.7\%), results suggest that they are more present in the residue by representing $12.7 \%$ of total phenolic constituents of persimmon waste. Flavonoid content of peel and calix appear to be markedly higher than the reported by other authors [44] for the whole fruit (different cultivars and ripening stages: 0.9-4.2 mg QE/100 g).

Regarding soluble tannins, results of the analysis reveal a remarkable low value. This is in line with the observed by other authors $[1,48]$, and it is most probably a consequence of the deastringency treatment with $\mathrm{CO}_{2}$. Soluble tannins are the polyphenol fraction responsible for persimmon unripe typical astringency [43] for which applying a $\mathrm{CO}_{2}$ postharvest treatment necessarily implies a reduction in the soluble tannins content. Exposure to $\mathrm{CO}_{2}$ activates anaerobic respiration in the fruit, which gives rise to an accumulation of acetaldehyde, which reacts with soluble tannins which become insoluble.

Carotenoids are responsible for the colour of persimmon fruit [49], $\beta$-carotene and lycopene being among the different carotenoids identified in persimmon and especially in persimmon peel [50]. $\beta$-carotene presence in the persimmon residues (peel and calyx) analysed in the present work (table 2) was in the range of the reported in the literature for persimmon peel. Veberic et al. [32] obtained values ranging from $239 \pm 28 \mu \mathrm{g} / 100 \mathrm{~g}$ in the peel of the Thiene cultivar to $875 \pm 50 \mu \mathrm{g} / 100 \mathrm{~g}$ in the peel of Tenjin O'Gosho cultivar. In turn, Giordani et al. [43] suggested that $\beta$-carotene content varies between $253 \pm 13$ and $420 \pm 100 \mu \mathrm{g} / 100 \mathrm{~g} \mathrm{FW}$ depending on the cultivar. Results of the present work also confirm that $\beta$-carotene content in persimmon peel and calyx is higher than in the whole fruit, $124 \mathrm{mg} / 100 \mathrm{~g}$ and $12-115 \mu \mathrm{g} / 100 \mathrm{~g}$, as reported by De Ancos et al. [51] and Zhou et al. [49], respectively.

As said, persimmon is also a richer source of lycopene than most commonly consumed fruits, with an average content of $159 \mu \mathrm{g} / 100 \mathrm{~g}$ [43]. Different investigations reveal considerable variability in the lycopene content of persimmon. Wright and Kader [52] found figures of $242 \mu \mathrm{g} / 100 \mathrm{~g}$ in the non-astringent Fuyu variety, whereas De Ancos et al. [51] obtained a content of $534 \mu \mathrm{g} / 100 \mathrm{~g}$ in the pulp of Rojo Brillante persimmon, higher 
than the obtained in the present study. Other authors [49] reported lycopene contents between 2.5 and $112 \mu \mathrm{g} / 100 \mathrm{~g}$ based on more than forty persimmon cultivars. Results varied significantly, regardless of the level of astringency. Variability in the lycopene content has been associated to the genotype effect or environmental factors such as exposure to light [43]. Other authors comment on factors such as the specific ripening state of the fruit [53]. According to the present study, persimmon residue constitutes a good source of lycopene, having obtained a content higher than the reported for the pulp, in average (table 2).

Finally, the antioxidant capacity of persimmon residue was calculated as Trolox Equivalents by the DPPH method, obtaining results in line with the reported by MartínezLas Heras et al. [54], who studied the influence of pre-harvest treatments on the antioxidant properties of Rojo Brillante persimmon during storage, and after $\mathrm{CO}_{2}$ postharvest deastringency treatment. As indicated previously, postharvest treatments with ethylene or $\mathrm{CO}_{2}$ cause a significant decrease in the antioxidant capacity of the fruit, up to 20-30\% according to Del Bubba et al. [1]. As compared to other fruit residues the antioxidant capacity of Rojo Brillante persimmon waste is in the lower range of the values reported for the water-soluble fraction of different fruit wastes [19]. $\mathrm{CO}_{2}$ deastringency treatment, as well as the high dependence on the extraction and quantification methods would explain this result.

\subsection{Persimmon waste (peel and calyx) as a source for bioethanol production}

As a lignocellulosic residual biomass, persimmon waste was analyzed as a source for the production of second-generation bioethanol. In addition to cellulose and hemicellulose, persimmon waste already contain an important amount of sugars directly available for fermentation (table 1) as it is the case of other fruit wastes proposed for bioethanol production [26]. As previously mentioned, 25\% water (v/v) was added to the grinded persimmon waste prior to fermentation. This mixture underwent thermal treatment (section 2.5.2) or was either directly fermented. In addition, the grinded persimmon waste was also subjected to a SSF process, either diluted in water or without water addition.

CFU count was registered every $24 \mathrm{~h}$ from the onset of fermentation to determine the adaptation of yeasts to the medium and their evolution during the process. Figure 3 summarizes the evolution of CFU content and total soluble solids (TSS) during this 
period. Initially, a sufficient amount of yeasts were inoculated in the medium so as to supersede the growth of other microorganisms that might contaminate the medium, particularly in the case of non-thermally treated samples. According to yeast growth during the first $24 \mathrm{~h}$ ([DF: 7 \pm 2 ; TTDF: 13 \pm 2 ; SSFd: $8.5 \pm 0.5$; SSFnd: $13 \pm 2] \times 10^{6}$ $\mathrm{CFU} / \mathrm{mL}$ ), microorganisms showed a good adaptation to the fermentation medium. These early hours of culture coincide with the exponential growth phase and were followed by a stationary phase in which microorganisms grew at a constant rate, showing the maximum CFU count at 48 hours ([DF: $8.3 \pm 1.6$; TTDF: $15.5 \pm 10.8$; SSFd: $12 \pm 2$; SSFnd: $\left.\left.13 \pm 1] \times 10^{6} \mathrm{CFU} / \mathrm{mL}\right]\right)$. The stationary phase was followed by a significant decrease in CFU in all cases (DF: $3.3 \pm 0.5$; TTDF: $6.8 \pm 1.2$; SSFd: $6.6 \pm 1.2$; SSFnd: $4.4 \pm 1.0] \times 10^{6}$ $\mathrm{CFU} / \mathrm{mL}]$ ), indicating the decline or death phase, which points towards the end of the fermentation process. These results were consistent with the TSS registered, since there were no changes in the soluble solids content between 48 and 72 hours, indicating no more microbial activity. Residual TSS were around 6 Brix degrees for all fermentations, including SSF processes.

Significant differences were found between the thermally and non-thermally treated residue, indicating that yeasts growth was favoured when other microorganisms present in the raw materials were eliminated thanks to the sterilization stage. On the other hand, it is deduced that performing a SSF process significantly improved microbial growth (SSF vs. DF on diluted samples). This could be a consequence of the improved access of the microorganisms to the nutrients while these are released from the medium, although other factors such as the reduced viscosity of the medium as a result of the saccharification process could also have influenced this result. SSF in the grinded persimmon waste (nondiluted) exhibited a CFU significantly higher, similar to the growth shown in the samples which underwent sterilization prior to fermentation. It is deduced that any difficulties for microorganisms' distribution would have been compensated by the increased sugar concentration, together, again, with the improved access to the nutrients when being released by the enzyme action; in addition, fluidification due to enzyme action could have improved yeast distribution. Besides, it should also be considered that increasing the solids load implies a culture medium closer to a solid state fermentation than to a submerged culture. Solid state fermentation has been claimed to be adequate for yeasts and may not only reduce substrate inhibition of microorganism growth [46] but also result in improved conversion rates. A slight $\mathrm{pH}$ decrease during the first 24 hours of 
fermentation ( $<0.5$ units, no significant differences among treatments) was also noticed in all cases, as a consequence of the organic acids resulting from yeast activity.

Evolution of sugars and ethanol production during DF and SSF processes is shown in figure 4. As expected, fermentable sugars decreased in line with an increase in the alcohol content along fermentation. In direct fermentation processes (Figure $4 \mathrm{a}$ and $3 \mathrm{~b}$ ), fermentation was considered to have finished $48 \mathrm{~h}$ after yeasts inoculation, which is in line with microorganisms growth plotted in figure 3. Lengthening the fermentation stage resulted in a decrease in the alcoholic content, which was more significant in the nonsterilized waste, probably as a result of the growth of other microorganisms such as acetic bacteria. As for the appropriateness to perform a thermal treatment prior to fermentation, results revealed no statistically significant differences ( $p$-value <0.05) as for ethanol production after 48 hour of fermentation. Nevertheless, the decrease in ethanol concentration after $72 \mathrm{~h}$ was slightly higher in the case of the non-thermally treated samples. In any case, it was considered that thermal treatment had no significant advantages over carrying out fermentation on unsterilized residue.

SSF was evaluated in the diluted (4c) and non-diluted waste (4d). Results indicated that SSF implied higher ethanol production than DF. Apart from the sugars initially present in the solid waste, SSF allows for the gradual generation of fermentable sugars as a result of complex carbohydrates hydrolysis, and further fermentation to produce bioethanol. This process decreases microorganism exposure to high sugars content and, consequently, substrate inhibition phenomena when saccharification is required. In addition, since cellulase is inhibited by glucose as it is formed, rapid conversion of glucose into ethanol by yeast results in faster rates, higher yields, and greater ethanol concentrations [55]. According to previous investigations in other lignocellulosic matrices to which similar enzyme loads had been added and similar process conditions had been applied [24, 26], hydrolytic action of enzymes is expected to have finished after $24 \mathrm{~h}$ of treatment. In the present study, a significant increase in bioethanol production during the first $24 \mathrm{~h}$ of treatment was observed, which continued up during the 72 hours registered, albeit at a much slower pace than previously. As stated previously, saccharification of the solid waste produces fluidification of the medium, which could have facilitated microorganism distribution and subsequent access to the substrate. SSF was even more successful when it was directly applied on the grinded persimmon waste, without water addition (Figure 
4d). Differences after 24, 48 and 72 hours of fermentation were significant as compared to the other three treatments applied (p-value <0.05). The amount of total sugars initially available for fermentation were also higher in this case, for which the alcohol increase was expected. In addition, advantages of solid state fermentation such as a better access to nutrients, lower substrate inhibition and higher yields [40], together with a reduced viscosity contributing to a proper distribution of microorganisms in the medium [39] would have contributed to the better results obtained in this case. In both SSF processes, fermentation could be considered to have finished after $24 \mathrm{~h}$, which is technically advantageous since processing time is of paramount importance at industrial level.

In order to evaluate microorganisms' activity in each case, yeast sugar conversion into ethanol, i.e. alcohol yield ( $\mathrm{g}$ of alcohol produced/g of sugar consumed) was calculated for the different treatments assayed (Table 3). First, it was evidenced that sterilizing the medium did not imply better yeast performance; in contrast, results revealed that SSF implies advantages versus DF, since ethanol yields were significantly higher for both SSF treatments (p-value $<0.05$ ). As in other studies [31, 56], SSF has been found to be a more effective treatment as a result of the simultaneous generation of fermentable sugars and fermentation, thus reducing yeast inhibition due to high sugar levels, which enhances yeast fermentation performance. Advantages of SSF were more evidenced when increasing the solid loading, since the best conversion yields were obtained for the SSF of the non-diluted waste.

\section{Conclusions}

Reintroducing added value compounds or products obtained from food waste materials in the economic cycle is of capital importance for the present food industry, given not only the environmental cost and waste management expenses, but also the potential economic and social benefits of the valorization process. The above mentioned particularities of Rojo Brillante persimmon, makes it necessary to find solutions for the valorization of this agri-food waste.

Results of the present work suggest that industrial persimmon residue may be a source of antioxidants and, especially, carotenoids. $\beta$-carotene and lycopene amounts in persimmon wastes have been found to be higher than in the whole fruit, which is a remarkable result since this fruit considered a good source of carotenoids. In contrast to extraction, which 
might constitute an expensive option, the use of a crude flour or powder from persimmon residue could represent a less expensive alternative and provide applications as functional ingredients, natural preservative, flavoring or coloring agents.

On the other hand, according to the increasing concern in the reduction of indirect land use change as a consequence of biofuel production and the need for the development of processes for the use of waste materials as a source for second generation bioethanol, persimmon residue has been assayed as a substrate for bioethanol production. Among the different processes assayed, the simultaneous saccharification and fermentation process resulted in higher ethanol yields and higher ethanol production because of the higher solid load which implied more sugars available for fermentation but reduced substrate inhibition phenomena. For bioethanol production, persimmon waste could be used alone or mixed with other with other food residual biomass. Results presented here could be valuable in order to develop integrated approaches for the valorization of persimmon residue.

\section{References}

1. Del Bubba, M., Giordani, E., Cincinelli, A., Checchini, L., and Galvan, P. Nutraceutical properties and sugar contents in astringent persimmons during on-tree growth and ripening and in response to different postharvest treatments. Journal of Food Composition and Analysis, 22 (2009): 668-677.

2. FAO. Food and Agriculture organization of the United Nations. http://www.fao.org.

3. Arnal, L. and Del Río, M. A. (2003). Removing astringency by carbon dioxide and nitrogen-enriched atmospheres in persimmon fruit cv. Rojo brillante. Journal of Food Science, 68, 1516-1518.

4. Lucas-González, R., Fernández-López, J., Pérez-Álvarez, J.A. and Viuda-Martos, M. (2018). Effect of particle size on phytochemical composition and antioxidant properties of two persimmon flours from Diospyros kaki Thunb. vars. 'Rojo Brillante' and 'Triumph' co-products. Journal of the Science of Food and Agriculture, 98:504-510.

5 Kim, Y.J, Lee, S.J., Kim, M.Y., Kim, G.R., Chung, H.S., Park, H.J., Kim, M.O. and Kwon, J.H. (2009). Physicochemical and Organoleptic Qualities of Sliced-dried 
Persimmons as Affected by Drying Methods. Korean Journal of Food Science and Technology, 41(1), 64-68.

6. Hernández-Carrión, M., Varela, P., Hernando, I., Fiszman, S.M. and Quiles, A. (2015). Persimmon milkshakes with enhanced functionality: Understanding consumers' perception of the concept and sensory experience of a functional food. LWT - Food Science and Technology 62, 384-392.

7. Han, L., Qi, S., Lu, Z. and Li, L. (2012). Effects of immature persimmon (Diospyros kaki linn. F.) juice on the pasting, textural, sensory and color properties of rice noodles. Journal of Texture Studies, 43 (3): 187-194.

8. Brun, C.A. (2015). Persimmons: An over-view of cultivars, production, harvesting, and marketing. Available on-line: http://ucce.ucdavis.edu/files/datastore/391-472.pdf.

9. Ghidelli, C., Mateos, M., Rojas-Argudo, C. and Pérez-Gago, M.B. (2013). Effect of antioxidants in controlling enzymatic browning of minimally processed persimmon Rojo Brillante. Postharvest Biology and Technology 86: 487-493.

10. Sanchís, E., Mateos, M. and Pérez-Gago, M. B. (2015). Effect of antibrowning dips and controlled atmosphere on the physico-chemical, visual and nutritional quality of minimally processed Rojo Brillante persimmons. Food Science and technology International, 23(1), 3-16.

11 Kim, S.K., Lee, G.D. and Jeong, S.K. (2003). Monitoring on fermentation of persimmon vinegar from persimmon peel. Korean Journal of Food Science and Technology, 35(4), 642-647

12. Ramachandraiah, K. and Chin, K.R. Effect of particle size of persimmon by-product powders on their physicochemical properties and antioxidant activities in porcine patties. Journal of Food Process Engineering, 41(1), 1-9

13. Martínez-Las Heras, R.,, Landines, E.F., Heredia, A., Castelló, M.L., Andrés, A. (2017). Influence of drying process and particle size of persimmon fibre on its physicochemical, antioxidant, hydration and emulsifying properties. Journal of Food Science and Technology, 54(9):2902-2912. 
14. George, A., and Redpath, S. Health and medicinal benefits of persimmon fruit: A review. Advances in Horticultural Science, 22(4) (2008): 244-249.

15. Takayuki, O. (2005). Persimmon: Your healthy autumn treats.Asahikawa Information, 108, 1-2 (In Japanese).

16. García-Alonso, M., de Pascual-Teresa, S., Santos-Buelga, C. and Rivas-Gonzalo, J.C. (2004). Evaluation of the antioxidant properties of fruits. Food Chemistry, 84(1), 13-18.

17. Jiménez-Sánchez, C., Lozano-Sánchez, J., Martí, N., Saura, D., Valero, M., SeguraCarretero, A. and Fernández Gutiérrez, A. (2015). Characterization of polyphenols, sugars, and other polar compounds in persimmon juices produced under different technologies and their assessment in terms of compositional variations. Food Chemistry, 182(1), 282-291.

18. Ayala-Zavala, J.F., Vega-Vega, V., Palafox-Carlos, H., Villa-Rodriguez, J.A., Wasim Siddiqui, Md., Dávila-Aviña, J.E. González-Aguilar, G.A. (2011). Agro-industrial potential of exotic fruit byproducts as a source of food additives. Food Research International, 44(7), 1866-1874.

19. Deng, G.-F.; Shen, C.; Xu, X.-R.; Kuang, R.-D.; Guo, Y.-J.; Zeng, L.-S.; Gao, L.-L.; Lin, X.; Xie, J.-F.; Xia, E.-Q.; Li, S.; Wu, S.; Chen, F.; Ling, W.-H. and Li, H.-B. (2012). Potential of Fruit Wastes as Natural Resources of Bioactive Compounds. International Journal of Molecular Sciences, 13: 8308-8323.

20. Song, C., Zhang, W., Pei, Y., Fan, G., and Xu, G. (2006). Comparative effects of MTBE and ethanol additions into gasoline on exhaust emissions. Atmospheric Environment, 40, 1957-1970.

21. Balat, M. (2011). Production of bioethanol from lignocellulosic materials via the biochemical pathway: A review. Energy Conversion and Management, 52: 858-875.

22. Chen, H.Z. and Qiu, W.H. (2010). Key technologies for bioethanol production from lignocellulose. Biotechnology Advances, 28: 556-562.

23. EU/2015/1513 Directive (EU) $2015 / 1513$ of the European parliament and of the council amending Directive 98/70/EC relating to the quality of petrol and diesel fuels and 
amending Directive 2009/28/EC on the promotion of the use of energy from renewable sources.

24. Conesa, C., Seguí, L. and Fito, P. (2018). Hydrolytic performance of Aspergillus niger and Trichoderma reesei cellulases on lignocellulosic industrial pineapple waste intended for bioethanol production. Waste and Biomass Valorization 9(8), 1359-1368.

25. Öhgren, K., Bura, R., Lesnicki, G., Saddler, J. and Zacchi, G. (2007). A comparison between simultaneous saccharification and fermentation and separate hydrolysis and fermentation using steam-pretreated corn stover. Process Biochemistry, 42 (5): 834-839

6. Seguí, L. and Fito, P. (2018). An integrated approach for pineapple waste valorisation. Bioethanol production and bromelain extraction from pineapple residues. Journal of Cleaner Production. Volume 172 (20), 2018, 1224-123.

27. Scheel, C. (2016). Beyond sustainability. Transforming industrial zero-valued residues into increasing economic returns. Journal of Cleaner production, 131(10), 376386.

28. Goula A.M. and Lazarides, H.N. (2015) Integrated processes can turn industrial food waste into valuable food by-products and/or ingredients: The cases of olive mill and pomegranate wastes. Journal of Food Engineering, 167, 45-50.

29. Mirabella, N., Castellani. V. and Sala, S. (2014). Current options for the valorization of food manufacturing waste: a review. Journal of Cleaner production, 65: 28-41.

30. AOAC, 1980 Association of official analytical chemist. Official Methods of Analysis, 20013. Washington, DC.

31. Van Soest, J.B. Robertson, B.A. Lewis. Methods for dietary fiber, neutral detergent fiber, and nonstarch polysaccharides in relation to animal nutrition

32. Veberic, R., Juhar, J., Mikulic-Petkovsek, M., Stampar, F., and Schmitzer, V. (2010). Comparative study of primary and secondary metabolites in 11 cultivars of persimmon fruit (Diospyros kaki L.). Food Chemistry, 119, 477-483. 
33. Singleton, V.L. and Rossi, J.A. (1965). Colourimetry of total phenolics with phosphomolybdic-phosphotungstic acid reagents. American Journal of Enology and Viticulture, 16, 144-158.

34. Luximon-Ramma, A.; Bahorun, T.; Soobrattee, M.A.; Aruoma, O.I. (2002). Antioxidant Activities of phenolic, proanthocyanidin, and flavonoid. components in extracts of Cassia fistula. J. Agric Food Chem., 50 (18): 5042-7.

35. Biehler, E., Mayer, F., Hoffman, L., Krause, E. and Bohn, T. (2010) Comparison of 3 Spectrophotometric Methods for Carotenoid Determination in Frequently Consumed Fruits and Vegetables. Journal of Food Science, 75(1), 55-61.

36. Cámara, M., Torrecilla, J.S., Cáceres, J.O., Cortes Sánchez Mata, M. and FernándezRuiz, V. (2010). Neural Network Analysis of Spectroscopic Data of Lycopene and $\beta$ Carotene Content in Food Samples Compared to HPLC-UV-Vis. Journal of the Agricultural and Food Chemistry, 58(1), 72-75.

37. Sadler, G., Davis, J. and Dezman, D. (1990). Rapid extraction of lycopene and bcarotene from reconstituted tomato paste and pink grapefruit homogenates. J. Food Sci. $55,1460-1461$.

38. Shahidi, F., Liyana-Pathirana, C. M., and Wall, D. S. (2006). Antioxidant activity of white and black sesame seeds and their hull fractions. Food Chemistry, 99, 478-483.

39. Sassner, P.; Galbe, M.; Zacchi, G. (2006). Bioethanol production based on simultaneous saccharification and fermentation of steam-pretreated salix at high drymatter content. Enzyme and Microbial Technology, 39: 756-762.

40. Soccol, c.R., Ferreira da Costa, E.S., Letti, L.A.J., Karp, S.C., Woiciechowski, A.L. and de Souza Vandenberghe, L.P. (2017). Recent developments and innovations in solid state fermentation. Biotechnology Research and Innovation, 1(1), 52-71.

41. Arshad, m., Hussain, t., Iqbal, M. and Abbas, M. (2017) Enhanced ethanol production at commercial scale from molasses using high gravity technology by mutant $\mathrm{S}$. cerevisiae Brazilian Journal of Microbiology, 48, 403-409 
42. Hirai, S., and Kondo, T. (2002). Problem in the saccharides analysis of the fruits and the countermeasure. Iida Joshi Tanki Daigadu Kiyo, 19, 59-68 (In Japanese).

43. Giordani, E., Doumett, S., Nin, S. and Del Bubba, M. (2011). Selected primary and secondary metabolites in fresh persimmon (Diospyros kaki Thunb.): A review of analytical methods and current knowledge of fruit composition and health benefits. Food Research International 44 (2011): 1752-1767.

44. Denev, P. and Yordanov, A. (2013). Total polyphenol, proanthocyanidin and flavonoid content, carbohydrate composition and antioxidant activity of persimmon (Diospyros kaki L.) fruit in relation to cultivar and maturity stage. Bulg. J. Agric. Sci., 19: $981-988$

45. Gorinstein, S., Zachwieja, Z., Folta, M., Barton, H., Piotrowicz, J., Zemser, M., Weisz, M., Trakhtenberg, S. and Martín-Belloso, O. (2001). Comparative content of dietary fiber, total phenolics and minerals in persimmon and apples. Journal of Agricultural and Food Chemistry, 49, 952-957.

46. Park, Y. S., Jung, S. T., Kang, S. G., Delgrado-Licon, E., Ayala, A. L. M., Tapia, M. S., Martín-Belloso, O., Trakhtenberg, S. and Goristein, S. (2006) Drying of persimmons (Dyospiros kaki L.) and the following changes in the studied bioactive compounds and the total radical scavenging activities. LWT-Food Science and Technology, 39 (2006): $748-755$.

47. Katsube, T., Tabata, H., Ohta, Y., Yamasaki, Y., Anuurad, E., Shiwaku, K. and Yamane, Y. (2004). Screening of antioxidant activity in edible plant products: comparison of low density lipoprotein oxidation assay, DPPH radical scavenging assay, and Folin-Ciocalteu assay. Journal of Agricultural Food Chemistry, 52, 2391-2396.

48. Salvador, A., Arnal, L., Besada, C., Larrea, V., Quiles, A. and I. Pérez-Munuera (2007). Physiological and structural changes during ripening and deastringency treatment of persimmon fruit cv. 'Rojo Brillante'. Postharvest Biol. Tec., 46, 181-188.

49. Zhou, C., Zhao, D., Sheng, Y., Tao, J. and Yang, Y. (2011). Carotenoids in Fruits of Different Persimmon Cultivars. Molecules, 16: 624-636. 
50 Daood, H. G., Biacs, P., Czinkotai, B., and Hoschke, A. Chromatographic investigation of carotenoids, sugars and organic acids from Diospyros kaki fruits. Food Chemistry, 45 (1992): 151-155.

51. De Ancos, B., Gonzales, E., and Cano, P. Effect of high-pressure treatment on the carotenoid composition and the radical scavenging activity of persimmon fruit purees. Journal of Agricultural and Food Chemistry, 48 (2000): 3542-3548.

52. Wright, K., and Kader, A. A. (1997). Effect of slicing and controlled-atmosphere storage on the ascorbate content and quality of strawberries and persimmons. Postharvest Biology and Technology, 10, 39-48.

53. Von Elbe, J. H. and Schwartz, S. J. (1996). Colorants. In O. R. Fennema (Ed.), Food Chemistry (pp. 651-722). New York: Marcel Dekker, Inc.

54. Martínez-Las Heras, R.; Amigo-Sánchez, J.C.; Heredia, A.; Castelló, M.L.; Andrés, A. (2016). Influence of preharvest treatments to reduce the seasonality of persimmon production on color, texture and antioxidant properties during storage, CyTA - Journal of Food, 14(2) 333-339.

55. Elumalai, S.; Thangavelu, V. (2010). Simultaneous Saccharification and fermentation (SSF) of pretreated sugarcane bagasse using Cellulase and Saccharomyces cerevisiae Kinetics and modelling. Chemical Engineering Research Bulletin, 14: 29-35.

56. Viikari, L., M.; Puranen, T., Vehmaanperä, J. and Siika-aho, M. (2007). Thermostable Enzymes in lignocellulose Hydrolysis. Advances in Biochemical Engineering/Biotechnology, 108: 121-145. 